\title{
Infecção natural por Listeria monocytogenes em cobaios Cavia porcellus
}

\author{
Natural infection by Listeria monocytogenes in guinea pigs (Cavia porcellus)
}

\section{Hugo Henrique Ferreira ${ }^{\mathrm{I}}$ Priscila Zlotowski ${ }^{\mathrm{I}}$ Tatiane Terumi Negrão Watanabe ${ }^{\mathrm{I}}$ Danilo Carloto Gomes $^{\mathrm{I}}$ Marisa Ribeiro Itapema Cardoso ${ }^{\mathrm{II}}$ David Driemeier $^{\mathrm{F}}$}

\section{- NOTA .}

\section{RESUMO}

Listeriose foi identificada em quatro porcos-daíndia (Cavia porcellus) enviados para diagnóstico postmortem.

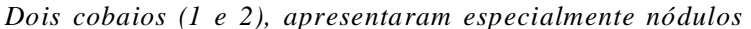
esbranquiçados multifocais no fígado e ceco, alterações que corresponderam microscopicamente a múltiplos focos necróticos associados com estruturas bacterianas basofílicas, degeneração gordurosa difusa e infiltrado linfocitário periportal. Lesões similares estavam presentes no intestino delgado, ceco e baço desses dois cobaios. Os outros cobaios (3 e 4) apresentavam exclusivamente alterações pulmonares caracterizadas por coloração avermelhada difusa e áreas esbranquiçadas multifocais na superfície pleural associadas histologicamente com infiltrado neutrofílico multifocal acentuado nos lúmens alveolar e bronquiolar, além de edema interseptal e alveolar, trombos vasculares e numerosos macrófagos alveolares (pneumonia supurativa). Em seções histológicas coradas pelo Brown-Hopps, foram identificadas estruturas bacilares Gram-positivas. A avaliação imunohistoquímica para anticorpos antiListeria monocytogenes revelou marcação fortemente positiva nos focos necróticos do fígado, ceco, baço, útero, estômago e linfonodos mesentéricos dos dois cobaios com listeriose sistêmica. Nos cobaios com pneumonia supurativa, observou-se intensa marcação nos lúmens alveolares. L. monocytogenes foi isolada de amostras de fígado e de casca de arroz utilizada como cama dos cobaios. Sugere-se que as lesões pulmonares foram consequentes à aspiração de partículas da cama de casca de arroz contaminada com L. monocytogenes.

Palavras-chave: doenças de cobaios, Listeriose, pneumonia, septicemia.

\section{ABSTRACT}

Listeriosis was identified in four guinea pigs (Cavia porcellus) received for post mortem evaluation. Two animals showed multifocal white nodules in the liver and cecum. These changes corresponded microscopically to multiple necrotic foci associated with basophilic bacterial structures, diffuse lipid vacuolation, and periportal lymphocytic infiltrates. Similar lesions were seen in the small intestine, cecum, and spleen of these two guinea pigs. The other two guinea pigs showed almost exclusively pulmonary changes that were characterized by diffuse red coloration and multifocal whitish areas in the pleural surface, which were microscopically associated with multifocal marked neutrophilic infiltrate within the alveolar and bronchiolar lumens, besides of interseptal and alveolar edema, vascular thrombi, and increased numbers of alveolar macrophages (suppurative pneumonia). The basophilic bacterial structures were Gram-positive for the Brown-Hopps special stain. The immunostaining antiListeria monocytogenes showed strong positive reactions in the necrotic foci of the liver, cecum, spleen, uterus, stomach, and mesenteric lymph node in the two guinea pigs with systemic listeriosis. The two guinea pigs with suppurative bronchopneumonia showed positive intense antiListeria monocytogenes immunostaining within the alveolar lumens. L. monocytogenes was isolated from samples of liver and rice hulls used as bedding material in the cages of the guinea pigs. It is suggested that the pulmonary changes observed here were caused by aspiration of particles of the rice hulls bedding contaminated with $\mathbf{L}$. monocytogenes.

Key words: Listeria monocytogenes, guinea pig diseases, septicemia, pneumonia.

IDepartamento de Patologia Clínica Veterinária, Universidade Federal do Rio Grande do Sul (UFRGS). Av. Bento Gonçalves, 9090, 91540-000, Porto Alegre, RS, Brasil. E-mail: davetpat@ufrgs.br. *Autor para correspondência.

IISetor de MedicinaVeterinária Preventiva, UFRGS, Porto Alegre, RS, Brasil. 
A Listeriose é uma doença causada principalmente pela Listeria monocytogenes, bactéria Gram-positiva não formadora de esporos e em formato de bastonete, amplamente distribuída na natureza, com habilidades para sobreviver em diferentes ambientes (RADOSTITS et al., 2002). A L . monocytogenes pode causar infecção localizada severa ou generalizada em humanos e em uma grande variedade de vertebrados domésticos ou selvagens (IIDA et al., 1998; VÁSQUEZBOLAND et al., 2001). As formas clínicas incluem infecção do útero gestante e aborto, septicemia com abscessos viscerais miliares e meningite e/ou encefalite (LECUIT, 2007; MAXIE \& YOUSSEF, 2007).

Em cobaios (Cavia porcellus), a infecção por $\boldsymbol{L}$. monocytogenes ocorre geralmente através da ingestão do agente e se expressa na forma septicêmica, mas outras formas, como queratoconjuntivite também podem ocorrer (COLGIN et al., 1995). Após a transmigração da barreira intestinal (LECUIT, 2007), a bactéria se replica nos hepatócitos e, por disseminação hematógena, pode chegar a vários outros órgãos, inclusive o útero (IRVIN et al., 2008). Roedores que morrem por listeriose apresentam, à necropsia, múltiplos focos brancos distribuídos aleatoriamente na superfície do fígado ou de outros órgãos, os quais, na microscopia, correspondem a focos de necrose, às vezes com formação de abscessos (DUSTOOR et al., 1977; IRVIN et al., 2008). Este trabalho descreve casos naturais de listeriose em cobaios Cavia porcellus de um biotério no Rio Grande do Sul e faz especial referência às lesões pulmonares observadas em dois cobaios.

Quatro cobaios foram necropsiados no Setor de Patologia Veterinária da Universidade Federal do Rio Grande do Sul, e fragmentos de diversos órgãos foram coletados, fixados em formalina a $10 \%$, processados conforme técnicas de rotina histológica e corados em hematoxilina-eosina (HE). Amostras de tecidos dos cobaios, ração e cama de casca de arroz (antes de ser utilizada) foram enviadas para isolamento bacteriológico segundo métodos propostos por QUINN et al. (1994). Cortes histológicos também foram submetidos à coloração de gram Brown-Hopps modificada e ao teste imuno-histoquímico (IHQ) anti $L$. monocytogenes $\left(\mathrm{BD}^{\circledR}\right.$, New Jersey, USA) pelo método de estreptavidina-biotina-peroxidase.

Estabeleceu-se o diagnóstico de listeriose com base nas alterações macroscópicas e microscópicas em associação com a identificação imuno-histoquímica e isolamento bacteriológico de Listeria monocytogenes. Dois desses quatro porcosda-índia tinham lesões associadas a bactérias intralesionais em vários órgãos (casos septicêmicos), e os outros dois, lesões e agente apenas no pulmão (listeriose pulmonar).

Achados macroscópicos nos dois casos de listeriose septicêmica ( 1 e 2) incluíram nódulos esbranquiçados multifocais com $0,3-0,7 \mathrm{~cm}$ de diâmetro na superfície capsular do fígado (Figura 1A) que, ao corte, estendiam-se ao parênquima hepático. Pontos esbranquiçados também foram observados na superfície serosa do ceco do Cobaio 1 . No Cobaio 2, observaram-se placas amareladas na mucosa do estômago, intestino e útero, além de conteúdo líquido no interior do ceco e cólon. Nos cobaios com listeriose pulmonar (3 e 4), os pulmões estavam difusamente avermelhados e apresentavam áreas multifocais esbranquiçadas na superfície pleural. As alterações macroscópicas no fígado dos Cobaios 1 e 2 corresponderam microscopicamente a múltiplos focos aleatórios de necrose associados a estruturas bacterianas basofílicas dispersas no parênquima hepático ou no citoplasma de hepatócitos. Havia também degeneração gordurosa difusa acentuada e infiltrado linfocitário periportal discreto. No intestino delgado e ceco de ambos (1 e 2), observou-se infiltrado linfocitário difuso moderado na mucosa e áreas de necrose multifocal de criptas, as quais apresentavam estruturas bacterianas basofílicas que por vezes foram observadas na submucosa e na camada muscular. No parênquima do baço e na mucosa uterina do Cobaio 1 , observava-se necrose multifocal. No baço do Cobaio 2, a necrose estava associada a estruturas bacterianas basofílicas multifocais discretas distribuídas no parênquima. Nos pulmões dos Cobaios 1 e 2, foram observados edema e congestão discretos. Os pulmões dos Cobaios 3 e 4 apresentavam infiltrado neutrofílico multifocal acentuado na luz de alvéolos e bronquíolos, edema interseptal e alveolar, trombos vasculares, além de grande número de macrófagos alveolares. $\mathrm{Na}$ coloração especial de Brown-Hopps modificada, as bactérias presentes nas áreas de necrose do fígado, baço e mucosa intestinal se demonstraram Grampositivas.

O teste de IHQ antiListeria monocytogenes revelou forte marcação nos focos de necrose do fígado (Figura 1B) e ceco (Figura 1C) dos Cobaios 1 e 2, além de marcação em baço, útero, estômago e linfonodo mesentérico do Cobaio 2. Os Cobaios 3 e 4 apresentaram broncopneumonia supurativa e forte marcação antiListeria monocytogenes no interior de alvéolos (Figura 1D). Listeria monocytogenes foi isolada no cultivo bacteriano a partir do fígado dos Cobaios 1 e 2 e da casca de arroz que seria utilizada como cama nas gaiolas.

O fígado de dois cobaios foi o órgão que apresentou lesões macroscópicas e microscópicas mais 


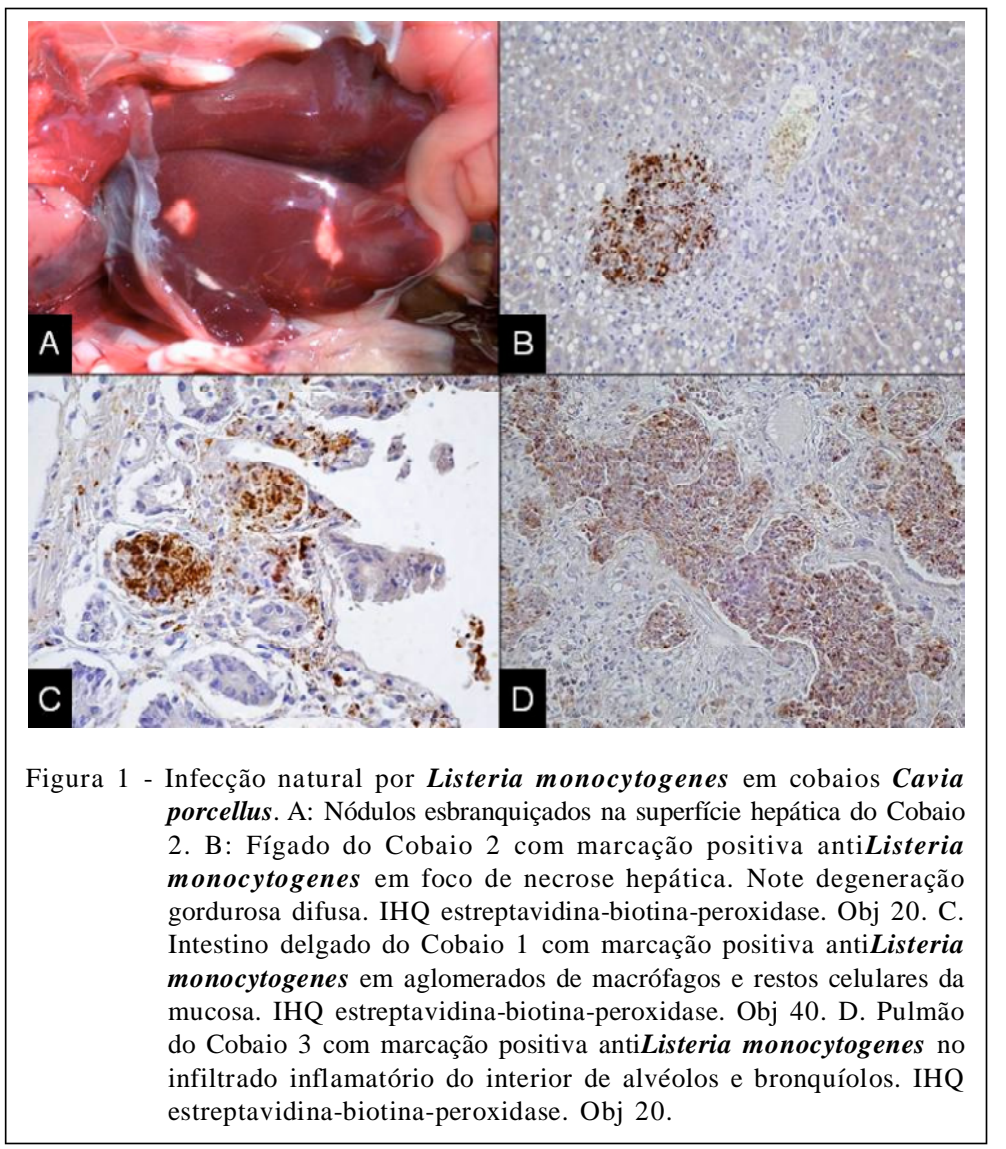

evidentes. A infecção hepática é explicada pela passagem intestinal da bactéria (VÁZQUEZ-BOLAND et al., 2001), que, nos casos estudados, pode estar associada com a ingestão da casca de arroz utilizada como cama nas gaiolas, ou alimento contaminado pelo contato com a cama.

Dois cobaios (3 e 4) apresentaram broncopneumonia supurativa associada com reações positivas na imuno-histoquímica antiListeria monocytogenes, mas sem alterações significativas em outros órgãos. Em experimento realizado em cobaios, após administração intravenosa, intraperitonial e intracardíaca de doses crescentes da bactéria, a lesão pulmonar observada consistia de espessamento das paredes alveolares e infiltrações de células inflamatórias mononucleares. Além disso, por se tratar de uma bacteremia induzida, focos de necrose e/ou inflamação em outros órgãos, como coração, fígado, baço e rins estavam frequentemente presentes (DUSTOOR et al., 1977). Dessa forma, a presença de lesões pulmonares, observadas nos dois casos deste estudo, e a ausência de lesões nos demais órgãos, sugere uma possível infecção aerógena, ainda não descrita nessa espécie.
É provável que a causa da listeriose septicêmica caracterizada por reação inflamatória da mucosa intestinal e por focos de necrose de enterócitos registrada em dois cobaios ( 3 e 4) tenha sido a ingestão de casca de arroz contaminada. A marcação imunohistoquímica antiListeria monocytogenes em lesões do fígado e intestino confirmaram a participação dessa bactéria como agente etiológico da doença.

A contaminação da casca de arroz usada como cama para os cobaios foi a fonte de infecção. As lesões digestivas e pulmonares indicaram as vias de acesso do agente. Dois cobaios com lesões entéricas, hepáticas e esplênicas caracterizaram a forma septicêmica da doença e as lesões restritas aos pulmões dos outros dois indicaram a forma pulmonar. Este trabalho demonstra que além de casos de septicemia, a Listeria monocytogenes deve ser considerada como agente causal de pneumonia em cobaios Cavia porcellus.

\section{AGRADECIMENTOS}

À Coordenação de Aperfeiçoamento de Pessoal de Nível Superior (CAPES) e ao Conselho Nacional de 
Desenvolvimento Científico e Tecnológico (CNPq), pelo apoio financeiro, e ao professor Cláudio Estevão Farias da Cruz, pela revisão deste artigo.

\section{REFERÊNCIAS}

COLGIN, L.M.A. et al. Case report of listerial keratoconjunctivitis in hairless guinea pigs. Laboratory Animal Science, v.45, p.435-436, 1995.

DUSTOOR, M. et al. Bacteriological and histopathological evaluation of guinea pigs after infection with Listeria monocytogenes. Infection and Immunology, v.15, p. 916924, 1977.

IIDA, T. et al. Detection of Listeria monocytogenes in humans, animals and foods. Journal Veterinary Medical Science, v.60, p.1341-1343, 1998. Disponível em: <http://dx.doi.org/ 10.1292/jvms.60.1341>. Acesso em: 04 dez. 2009. doi: $10.1292 /$ jvms.60.1341.

IRVIN, E.A. et al. Listeria monocytogenes infection in pregnant guinea pigs is associated with maternal liver necrosis, a decrease in maternal serum TNF-a concentrations, and an increase in placental apoptosis. Reproductive Toxicology, v.26, p.123129, 2008. Disponível em: <http://dx.doi.org/10.1016/ j.reprotox.2008.07.007>. Acesso em: 10 jan. 2010. doi: $10.1016 /$ j.reprotox.2008.07.007.

LECUIT, M. Human listeriosis and animal models. Microbes and Infections, v.9, p.1216-1225, 2007. Disponível em: <http://dx.doi.org/10.1016/j.micinf.2007.05.009>. Acesso em: 10 jan. 2010. doi: 10.1016/j.micinf.2007.05.009.

MAXIE, M.G.; YOUSSEF, S. Nervous system. In: MAXIE, M.G. Jubb, Kennedy and Palmer's pathology of domestic animals. 5.ed. Philadelphia: Saunders Elsevier, 2007. V.1, p. $405-408$.

QUINN, P.J. et al. Clinical veterinary microbiology. London: Wolfe, 1994. p.170-173.

RADOSTITS, O.M. et al. Clínica veterinária: um tratado de doenças dos bovinos, ovinos, suínos, caprinos e eqüinos. 9.ed. Rio de Janeiro: Guanabara Koogan, 2002. p.661-666.

VÁZQUEZ-BOLAND, J.A. et al. Listeria pathogenesis and molecular virulence determinants. Clinical Microbiology Reviews, v.14, p.584-640, 2001. Disponível em: <http:// dx.doi.org/10.1128/CMR.14.3.584-640.2001>. Acessado em: 03 fev. 2010. doi: 10.1128/CMR.14.3.584-640.2001. 